\title{
Age Related Changes in Pinealocytes of the Pineal Gland in Bangladeshi Cadavers
}

\author{
Halima Afroz ${ }^{1}$, Abu Sadat Mohammad Nurunnabi², Mushfika Rahman ${ }^{3}, K_{\text {Kanij Fatema }}^{4}$, \\ Shamim Ara ${ }^{5}$
}

\begin{abstract}
Background: The pineal gland (epiphysis cerebri) contains cords and follicles of pinealocytes and neuroglia. Objective: To determine the number of the pinealocytes and neuroglial cells per sq. $\mathrm{mm}$ of microscopic field in different age group in a Bangladeshi population to view the age related change. Methods: This cross-sectional study was done in the Department of Anatomy, Dhaka Medical College, Dhaka, from July 2009 to June 2010, based on the collection of 60 pineal glands from whole human brains of unclaimed dead bodies from the morgue. All the samples were divided into four age-groups: 15-30 years, 31-40 years, 41-50 years and $>50$ years. Histological slides were prepared by using routine Harris' Haematoxylin and Eosin (H \& E) stain. The number of pinealocytes and neuroglial cells per sq. mm of the microscopic field were determined by point counting technique, using ocular micrometer. For statistical analysis, ANOVA and independent sample t test were used. Results: The mean number of pinealocytes and neuroglial cells were found $10875.00 \pm 649.75$ and $606.31 \pm 94.52$ in group15-30 years, 9738.83 \pm 761.35 and 631.57 \pm 94.52 in group31-40 years 31-40 years, $9637.78 \pm 382.02$ and $568.41 \pm 69.57$ in group $41-50$ years and $8134.64 \pm 358.07$ and $766.31 \pm 248.00$ in group $>50$ respectively. Age related significant differences were found in number of pinealocytes in 15-30 years vs 31-40 years, 15-30 years vs 41-50, 15-30 years vs $>50,31-40$ years vs $>50$ and 41-50 vs $>50$ years. However, no differences were found in number of neuroglial cells among different age groups. Conclusion: This study showed progressive degeneration of pinealocytes with advancing age. However, no age related changes were found in number of neuroglial cells.
\end{abstract}

Key words: Pineal gland, pinealocyte, neuroglial cells, pineal secretion, pineal function.

J Bangladesh Soc Physiol. 2016, June; 11(1): 18-22

For Authors Affiliation, see end of text.

http://www.banglajol.info/index.php/JBSP

\section{Introduction}

$\mathbf{T}$ he pineal gland (epiphysis cerebri) contains cords and follicles of pinealocytes and neuroglia ${ }^{1,2}$. Pinealocytes form the pineal parenchyma and exert pineal secretion. Neuroglial cells, partially separating the pinealocytes, are like astrocytes ${ }^{1}$. Currently, it is considered that pineal secretions modulate the activity of the adenohypophysis and

Received 10th Dec. 2015; Accepted 4th April 2016 neurohypophysis, the thyroid and parathyroids, adrenal cortex and medulla, endocrine pancreas and the gonads ${ }^{2,3}$. The overall effect of these substances appears to be to regulate the proper timing of various activities, affecting daily 'circadian' rhythmicity (such as the sleep-wake cycle) or seasonal activities (e.g. hibernation, reproduction in seasonally reproductive lower animals $)^{4}$. Recent research suggests some possible roles of pineal gland in 
immunomodulation ${ }^{5}$ and even the induction of malignancy ${ }^{6}$. However, in the literature, results are scarce about the existence of a relationship between pineal secretion and pineal size and/or tissue composition of the pineal gland ${ }^{7}$. To some extent, nuclear size had been used to assess varying degree of activity in the pineal gland in experimental animals ${ }^{8}$. Moreover, it was found in sheep that functional activity of pineal gland was related to the number of pinealocytes and not with their size ${ }^{7}$. Progressive degeneration of pinealocytes and, in some cases, reciprocal increase of neuroglial cells with advancing age was reported in humans ${ }^{9,10}$, and a decrease in secretory activity of pinealocytes had also been observed ${ }^{10,11}$. Hence, due to several controversial reports on pinealocytes from different parts of the world and unavailability of such work; in this regard, in our country, we proposed to investigate microscopically the effects of advancing age on cell population of the pineal gland among our local population, by using cadaveric material. The present study was done to determine the number of the pinealocytes and neuroglial cells in different age group and to correlate with the previous studies. The results of the present study are expected to be contributory to the information pool for the researchers in anatomy, physiology, pathology, radiology, neurology and psychology.

\section{Methods}

A cross-sectional, descriptive study was designed and done in the Department of Anatomy, Dhaka Medical College, Dhaka, from July 2009 to June 2010 , to determine the number of the pinealocytes and glial cells.

The present study was performed on 60 human pineal glands collected from whole human brains of unclaimed dead bodies that were under postmortem examination in the Department of Forensic Medicine, Dhaka Medical College, Dhaka. This study was approved by the Ethical Review Committee of Dhaka Medical College, Dhaka. After the legal formalities, whole of the human brain was collected within 24-36 hours of death. During collection of the samples, appropriate age, sex and the cause of death were noted from the morgue's record book. The samples were tagged immediately bearing code numbers for subsequent identification. Soon after collection, each sample was gently washed with tap water on a dissection tray. Blood and blood clots were removed as far as possible.

Preservation of brains: After collection of whole brain, $100 \mathrm{ml}$ of $40 \%$ formaldehyde solution was injected by using a 50cc syringe into the brain through the surfaces (superolateral and inferior surfaces). Then it was preserved in $40 \%$ formaldehyde solution for 15 days. After 15 days the pineal glands were collected from the preserved brains and the pineal gland fixed in $10 \%$ formol saline solution.

Procedure of collection of pineal gland from preserved brain: After fixation of the whole of the human brain, the pineal gland was collected by the following steps:

At first, the fingers were placed in the medial part of the horizontal fissure of the left half of the cerebellum and it was separated. Thus the total of the superior and parts of the middle and inferior cerebellar peduncles were exposed. The thin layer of the white matter near the posterior border of the cerebellum was picked up by using a blunt forceps. Exposing the superior cerebellar peduncles, the pineal gland was identified in between the depression of the superior colliculi and observed that it was attached to the dorsal surface of the brain, at the junction of the midbrain and the diencephalon and inferior to the splenium of the corpus callosum ${ }^{12}$. An incision of about 1-2 cm was given through the splenium of the corpus callosum to approach the pineal region. The pineal gland was taken out from the diencephalon with a careful semilunar cut $^{9}$. The pineal gland was cleared up from other tissues. Then, it was preserved in a small plastic jar containing 10\% formol saline solution for further histological procedures. While selecting cadavers the researchers were cautious not to include samples from any decomposed body, any history of injury to the head, any suspected pathology of the pineal gland seen by naked eyes, 
and if the whole of the pineal gland is not available during dissection.

All the samples were categorized in four agegroups: $15-30$ years, 31-40 years, 41-50 years and $>50$ years, according to Golan et al. ${ }^{13}$, for convenient description of their various age related changes.

Preparation of the slide: Tissue blocks were fixed in $10 \%$ formol saline in a plastic container. The tissues were washed in running tap water, dehydration was done with ascending grades of alcohol, cleared with xylene, infiltrated and embedded in paraffin. Paraffin blocks were cut at $5 \mathrm{~mm}$ thickness and were stained with routine Harris' Haematoxylin and Eosin (H \& E) stain. The light compound microscope which was used for the microscopic measurement was OLYMPUS CHB, made in Tokyo, Japan.

For estimation of the number of the pinealocytes and neuroglial cells per sq. mm. area of the microscopic field, 7 best prepared slides were taken from group 15-30 years, 31-40 years and $41-50$ years, while 6 from group $>50$. Histological slides were examined under the light microscope in low magnification $(\times 10$ objectives, $\times 10$ eyepiece). The stained tissue section on the slide was divided into three equal parts by a computer generated, photographically produced equal sized room over a transparent plastic sheet by drawing three lines which radiated from the centre towards the periphery at 10 o'clock, 2 o'clock and 6 o'clock position. Then, this sheet was fixed on the top of the cover slip by an adhesive tape. The centre of this sheet corresponded with the centre of the tissue section. From each triangular area, one microscopic field was selected near the centre for study. Thus from each slide, three different fields were chosen for counting the number of pinealocytes and neuroglial cells. The counting was done within a counting circle specially devised for this purpose. A counting circle of $5 \mathrm{~mm}$ diameter was printed on a transparent plastic sheet, which was cut to fit into the eyepiece of the light microscope. Thus, a black circular outline was superimposed over the actual microscopic field. The circle encircled few whole of the pinealocytes/glial cells, while other pinealocytes/glial cells were also included partially (one-half, one-fourth, three-fourths etc.) inside that counting circle. However, the rest of the cells were also seen. Considering this circle as the field to be studied (rather than the whole microscopic field), the portions of the follicles inside this field were taken in consideration by an eye estimate e.g. 1, 0.75, 0.5, 0.25 etc. From the three counts of three different fields of each slide, an average count was calculated for each slide. Thus the average counts of 90 fields for each group were available. The count was then converted into number per square $\mathrm{mm}$ by conversion measurement by means of an ocular micrometer and a stage micrometer according to Nurunnabi et al. ${ }^{14}$

Data were expressed as mean \pm SD. The comparison between different age groups were done by One-way ANOVA and independent sample t test. All the statistical analyses were done by using the SPSS 13.0.

\section{Results}

The light microscopic examination of the samples of pineal glands showed that the parenchyma is composed of pinealocytes and neuroglial cells; former were arranged as cords or clusters and the latter as few scattered cells among them. Pinealocyte varied from round to oval in shape; their pale staining nuclei were also round to oval in shape and larger than those of the neuroglial cells (Figure 1).

The mean \pm SD number of pinealocytes and neuroglial cells were found $10875.00 \pm 649.75$ and $606.31 \pm 94.52$ in age group 15-30 yrs, $9738.83 \pm 761.35$ and $631.57 \pm 94.52$ in age group $31-40 \mathrm{yrs}, 9637.78 \pm 382.02$ and $568.41 \pm 69.57$ in age group 41-50 yrs and 8134.64 \pm 358.07 and $766.31 \pm 248.00$ in age group $>50 \mathrm{yrs}$, per sq. $\mathrm{mm}$ of microscopic field respectively (Table I). Age related significant differences were found in number of pinealocytes in 15-30 yrs vs 31-40 yrs, 15-30 yrs vs 41-50 yrs, 15-30 yrs vs $>50$ yrs, 31-40 yrs vs $>50$ yrs and 41-50 yrs vs $>50$ yrs. These results showed the progressive degeneration of pinealocytes with advancing age. However, no difference was found in number of neuroglial cells among different age groups (Table I). 
Table I Cell count of pineal gland per sq. mm of microscopic field in different age group

\begin{tabular}{|c|c|c|c|c|}
\hline Cells & $\begin{array}{c}15-30 \text { yrs } \\
(n=7)\end{array}$ & $\begin{array}{c}31-40 \text { yrs } \\
(n=7)\end{array}$ & $\begin{array}{c}41-50 \text { yrs } \\
(n=7)\end{array}$ & $\begin{array}{c}>50 \text { yrs } \\
(n=6)\end{array}$ \\
\hline Pinealocytes & $10875.00 \pm 649.75$ & $9738.83 \pm 761.35^{* *}$ & $9637.78 \pm 382.02^{\dagger \dagger}$ & 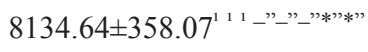 \\
\hline ( no.) & (9460.94-11406.18) & $(8753.58-10610.40)$ & (9018.84-10256.72) & $(7780.96-8753.58)$ \\
\hline Neuroglial & $606.31 \pm 94.52$ & $631.57 \pm 94.52$ & $568.41 \pm 69.57$ & $766.31 \pm 248$ \\
\hline cells (no.) & $(530.52-795.78)$ & $(440.12-707.36)$ & $(442.10-618.94)$ & $(42.10-1061.04)$ \\
\hline
\end{tabular}

Data are expressed as mean $\pm \mathrm{SD}$. Figures in parentheses indicate range. Statistical analysis done by oneway ANOVA (PostHoc) test. ${ }^{* *} \mathrm{P}<0.01,31-40 \mathrm{yr}$ vs15-30yrs; $\dagger \dagger \mathrm{P}<0.01,41-50 \mathrm{yrs}$ vs15-30yrs; ${ }^{1} 11$ $\mathrm{P}<0.001>50 \mathrm{yrs}$ vs $15-30 \mathrm{yrs}$; -" -" -" $\mathrm{p}<0.001>50$ yrs vs $31-40 \mathrm{yrs}$ *"*”P $<0.01>50 \mathrm{yrs}$ vs41-50 yrs.

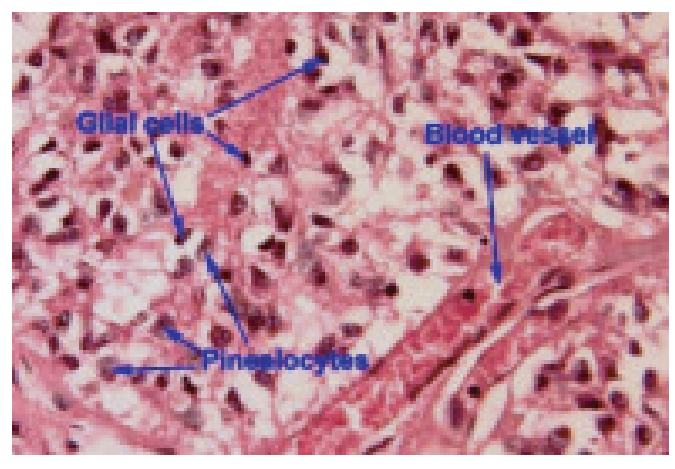

Figure 1: Cells of the human pineal gland taken from group (31-40 years), $(\times 100$ magnification) [H \& E stain].

\section{Discussion}

Previous biochemical and physiological studies pointed to an age-related loss of pineal function. Morphological studies revealed increased connective tissue and glial cell numbers in the gland with ageing in experimental animals. Agerelated decrease in the number of pinealocytes with simultaneous increase in amount of glial fibers is also evident in humans ${ }^{9,10,15}$. Rabia et al. ${ }^{16}$ studied thirty pineal glands from human cadavers ranging from 16 to 80 years of age. They found mean number of pinealocytes were 160,151 and 122 in age group 16-30 years, 3145 years and $46-80$ years respectively. In their study the number of pinealocytes decreased with aging but the difference was not statistically significant. Besides, there was no change in size of pinealocyte soma and its nucleus. They reported that the number and size of pinealocytes, and their nuclei remained unaltered with advancing age. However, the findings of the present study differ with those of Rabia et al. ${ }^{16}$. In the present study, though age effect on progressive degeneration of pinealocytes were observed however, no age related changes were found in number of neuroglial cells. Several studies reported agerelated decline in pineal metabolism and function which may be due to decreased parenchymal cell numbers both in humans ${ }^{17,18}$ and experimental animals ${ }^{15}$. The findings of this study also supports this natural phenomenon of age related regression in the pineal gland.

\section{Conclusion}

This study concluded that the progressive degeneration of pinealocytes may occur with advancing age. Further studies with larger samples, advanced stereological technique and further analysis by correlating the structure with the function of the pineal gland using ultra structural study and serum melatonin level with advancing age in an advanced laboratory set up are recommended.

\section{Conflict of interest: None}




\section{Author Affiliation}

1. Halima Afroz, Associate Professor, Department of Anatomy, Green Life Medical College, Dhaka.

2. Abu Sadat Mohammad Nurunnabi, Assistant Professor, Department of Anatomy, OSD, Directorate General of Health Services (DGHS), Dhaka. Bangladesh. Cell Phone: +8801712290608, Email: shekhor19 (a)yahoo.com

3. Mushfika Rahman, Associate Professor, Department of Anatomy, Dr. Sirajul Islam Medical College, Dhaka.

4. Kanij Fatema, Associate Professor, Department of Anatomy, Jahurul Islam Medical College, Bajitpur, Kishoreganj.

5. Shamim Ara, Professor \& Head, Department of Anatomy, Dhaka Medical College, Dhaka.

* For correspondence

\section{References}

1. Snell RS. Clinical anatomy by regions. $8^{\text {th }}$ ed. Baltimore: Lippincott Williams \& Wilkins; 2008. p.816-17.

2. Crossman AR. Neuroanatomy. In: Standring S, Ellis H, Healy JC, Johnson D, Williams A, Collins P eds. Gray's anatomy: the anatomical basis of clinical practice. Edinburgh: Elsevier Churchill Livingstone; 2005. p.324.

3. Lukaszyk A, Reiter RJ. Histophysiological evidence for the secretion of polypeptides by the pineal gland. Am J Anat 1975; 143(4): 451-64.

4. Underwood H. Endogenous rhythms. In: Gans C, Crews D, eds. Biology of the Reptilia: Volume 18. Physiology E: Hormones, Brain and Behaviour. Chicago: University of Chicago Press; 1992. p.229-97.

5. Guerrero JM, Reiter RJ. Melatonin-immune system relationships. Curr Top Med Chem 2002; 2(2): 167-79.

6. Penev PD, Zee PC. Melatonin: a clinical perspective. Ann Neurol 1997; 42(4): 545-53

7. Gómez Brunet A, Malpaux B, Daveau A, Taragnat C, Chemineau P. Genetic variability in melatonin secretion originates in the number of pinealocytes in sheep. J Endocrinol 2002; 172(2): 397-404.
8. Tapp E. The histology and pathology of the human pineal gland. Prog Brain Res 1979; 52: 481-500.

9. Anti S, Javanovi I, Stefanovi N, Pavlovi S, Ran i G, Ugrenovi S. Morphology and histochemical characteristics human pineal gland acervuli during the aging. Facta Universitatis. Med Biol 2004; 11(2): 63-8.

10. Koshy S, Vettivel SK. Varying appearances of calcification in human pineal gland: a light microscopic study. J Anat Soc India 2001; 50(1): 17-8.

11. Vígh B, Szél A, Debreceni K, Fejér Z, Manzano e Silva MJ, Vígh-Teichmann I. Comparative histology of pineal calcification. Histol Histopathol 1998; 13(3): 851-70.

12. Romanes GJ ed. Cunningham's manual of practical anatomy. Vol.3, New York: Oxford University Press; 2000: p.244-5.

13. Golan J, Torres K, Sta[kiewicz GJ, Opielak G, Maciejewski R. Morphometric parameters of the human pineal gland in relation to age, body weight and height. Folia Morphol 2002; 61(2): 111-3.

14. Nurunnabi ASM, Mahbub S, Shahriah S, Begum GN, Ara S. Thyroid follicles and parenchyma are found to increase with advancing age during the first 50 years of life in Bangladeshi people. J Bangladesh Soc Physiol 2009; 4(2): 88-92.

15. Reuss S, Spies C, Schröder H, Vollrath L. The aged pineal gland: reduction in pinealocyte number and adrenergic innervation in male rats. Exp Gerontol 1990; 25(2): 183-8.

16. Rabia A, Tahir M, Munir B, Sami W. Quantitative and qualitative analysis of cadaveric human pinealocytes in various age groups. J Coll Phys Surg Pak 2011; 21(7): 389-92.

17. Al-Hussain SM. The pinealocytes of the human pineal gland: a light and electron microscopic study. Folia Morphol 2006; 65(3): 181-7.

18. Tapp E, Huxley M. The histological appearance of the human pineal gland from puberty to old age. J Pathol 1972; 108(2): 137-44. 